\title{
Effect of a care transition intervention by pharmacists: an RCT
}

\author{
Karen B Farris ${ }^{1 *}$, Barry L Carter ${ }^{2,3}$, Yinghui X ${ }^{3}$, Jeffrey D Dawson ${ }^{4}$, Constance Shelsky ${ }^{2}$, David B Weetman ${ }^{2,5}$,
} Peter J Kaboli ${ }^{5,6,7}$, Paul A James ${ }^{3,5}$, Alan J Christensen ${ }^{6,8}$ and John M Brooks ${ }^{9}$

\begin{abstract}
Background: Pharmacists may improve medication-related outcomes during transitions of care. The aim of the lowa Continuity of Care Study was to determine if a pharmacist case manager (PCM) providing a faxed discharge medication care plan from a tertiary care institution to primary care could improve medication appropriateness and reduce adverse events, rehospitalization and emergency department visits.

Methods: Design. Randomized, controlled trial of 945 participants assigned to enhanced, minimal and usual care groups conducted 2007 to 2012. Subjects. Participants with cardiovascular-related conditions and/or asthma or chronic obstructive pulmonary disease were recruited from the University of lowa Hospital and Clinics following admission to general medicine, family medicine, cardiology or orthopedics. Intervention. The minimal group received admission history, medication reconciliation, patient education, discharge medication list and medication recommendations to inpatient team. The enhanced group also received a faxed medication care plan to their community physician and pharmacy and telephone call 3-5 days post-discharge. Participants were followed for 90 days post-discharge. Main Outcomes and Measures. Medication appropriateness index (MAl), adverse events, adverse drug events and post-discharge healthcare utilization were compared by study group using linear and logistic regression, as models accommodating random effects due to pharmacists indicated little clustering.
\end{abstract}

Results: Study groups were similar at baseline and the intervention fidelity was high. There were no statistically significant differences by study group in medication appropriateness, adverse events or adverse drug events at discharge, 30-day and 90-day post-discharge. The average MAl per medication as 0.53 at discharge and increased to 0.75 at 90 days, and this was true across all study groups. Post-discharge, about 16\% of all participants experienced an adverse event, and this did not differ by study group ( $p>0.05$. Almost one-third of all participants had any type of healthcare utilization within 30 days post-discharge, where $15 \%$ of all participants had a 30-day readmission. Healthcare utilization post-discharge was not statistically significant different at 30 or 90 days by study group.

Conclusion: The pharmacist case manager did not affect medication use outcomes post-discharge perhaps because quality of care measures were high in all study groups.

Trial registration: Clinicaltrials.gov registration: NCT00513903, August 7, 2007.

Keywords: Clinical pharmacist, Care transitions, Continuity of care, Medication reconciliation, Medication care plan

\footnotetext{
* Correspondence: kfarris@umich.edu

${ }^{1}$ College of Pharmacy, University of Michigan, 428 Church St, Ann Arbor, MI

48109-1065, USA

Full list of author information is available at the end of the article
} 


\section{Background}

Transitions across care settings are a critical time to manage medications [1-6]. Up to two-thirds of individuals have unintended medication discrepancies at admission, and medication changes made during the hospitalization are not always conveyed to primary care providers following discharge. Rehospitalization is particularly important today as Medicare policy now reduces payments to health systems for specified conditions where rates do not meet target goals. Thus, improving care during transitions is critical. With medications as one important aspect of care coordination, involving pharmacists in these processes may be helpful [7-10].

Medication reconciliation has been advocated to reduce medication discrepancies [6-8,11], and is defined as the development of a medication list that is as accurate as possible, which is compared at admission, transfer or discharge, to help ensure correct medications at transitions [11]. However, up-to-date discharge medication lists do not ensure the correct medications are obtained and used. In fact, two recent reviews examined the impact of medication reconciliation $[7,8]$ and stated that it alone was not likely to improve post-discharge utilization, yet it reduced medication discrepancies, potential adverse drug events and adverse drug events [10,11]. Hesselink et al. noted that about half the studies showed improvements in adverse events or healthcare utilization postdischarge and noted the difficulty in comparing interventions across studies because of their complexity, lack of detail, varying outcomes and variability in study execution [9]. Thus, numerous well-designed studies have been reported, but the evidence is not consistent, and further studies are needed to examine how discharge processes can be improved to achieve optimal outcomes.

We previously reported the methods for the Iowa Continuity of Care Study [12]. The aim of the Iowa Continuity of Care Study was to determine if a pharmacist case manager (PCM) providing a faxed discharge medication care plan from a tertiary care institution to primary care could improve medication appropriateness and reduce adverse events, rehospitalization and emergency department visits. The major goal was to improve communication links between the tertiary hospital, the primary care physician and community pharmacists, and these providers typically received communication from the institution by mail (primary care physician) or not at all (community pharmacists). The hypotheses were: (1) Medication appropriateness will be improved in patients receiving care from PCM versus usual care; (2) Adverse drug events $(\mathrm{ADE})$ will be lower post-discharge in patients receiving care from PCM versus usual care and (3) Number of readmission, emergency department visits or unscheduled office visits will be lower in patients receiving care from PCM versus usual care.

\section{Methods}

\section{Design}

This study was a randomized, controlled trial where participants were assigned to one of three study groups including enhanced, minimal and control/usual care conducted from 2007 to 2012 (Figure 1) [12]. This study was conducted in one Midwestern academic health center, and the study was approved by University of Iowa and University of Michigan Institutional Review Boards.

\section{Subjects}

Electronic medical records were reviewed, and individuals meeting the inclusion criteria were visited in hospital by trained research assistants to determine eligibility and obtain informed consent. Recruitment occurred MondayFriday on four services from 2008 through 2011 and we talked with 10-12 admitted patients per week who met the inclusion criteria. Participants were typically enrolled into the study within 1 day after admission and randomized to study group using the statistician-generated blinded randomization scheme with sequentially numbered envelopes. The intervention in the enhanced or minimal intervention groups began immediately after randomization with a visit from a study pharmacist and, if subjects were in the enhanced intervention group, it continued for 3-5 days post-discharge when participants were telephoned. Pharmacists were unaware of whether participants were assigned to the enhanced or minimal intervention group until discharge. For the outcome data, all study participants were followed for 90 days post-discharge.

Participants were recruited from general medicine, family medicine, cardiology or orthopedics. The inclusion criteria were English or Spanish speaker, 18 years or older, admitted with diagnosis of hypertension, hyperlipidemia, heart failure, coronary artery disease, myocardial infarction, stroke, transient ischemic attack, asthma, chronic obstructive pulmonary disease or receiving oral anticoagulation. These conditions were focused on in this study because of previous work we had completed among patients with cardiovascular conditions where pharmacists had impacted their clinical outcomes. Individuals were excluded if they were admitted to psychiatry, surgery or hematology/oncology service, could not use a telephone, had life expectancy $<6$ months, had dementia or cognitive impairment or had a severe psychiatric diagnosis. These individuals were excluded because they may have had difficulty completing all aspects of the study. In addition, participants were excluded if they received primary care or prescriptions from University of Iowa Hospital and Clinics (UIHC) with shared medical record access. The reason for this exclusion was to include providers external to UIHC to determine if the intervention could improve communication to primary care providers. We randomized 945 participants, and 9 participants (3 from each study group) 


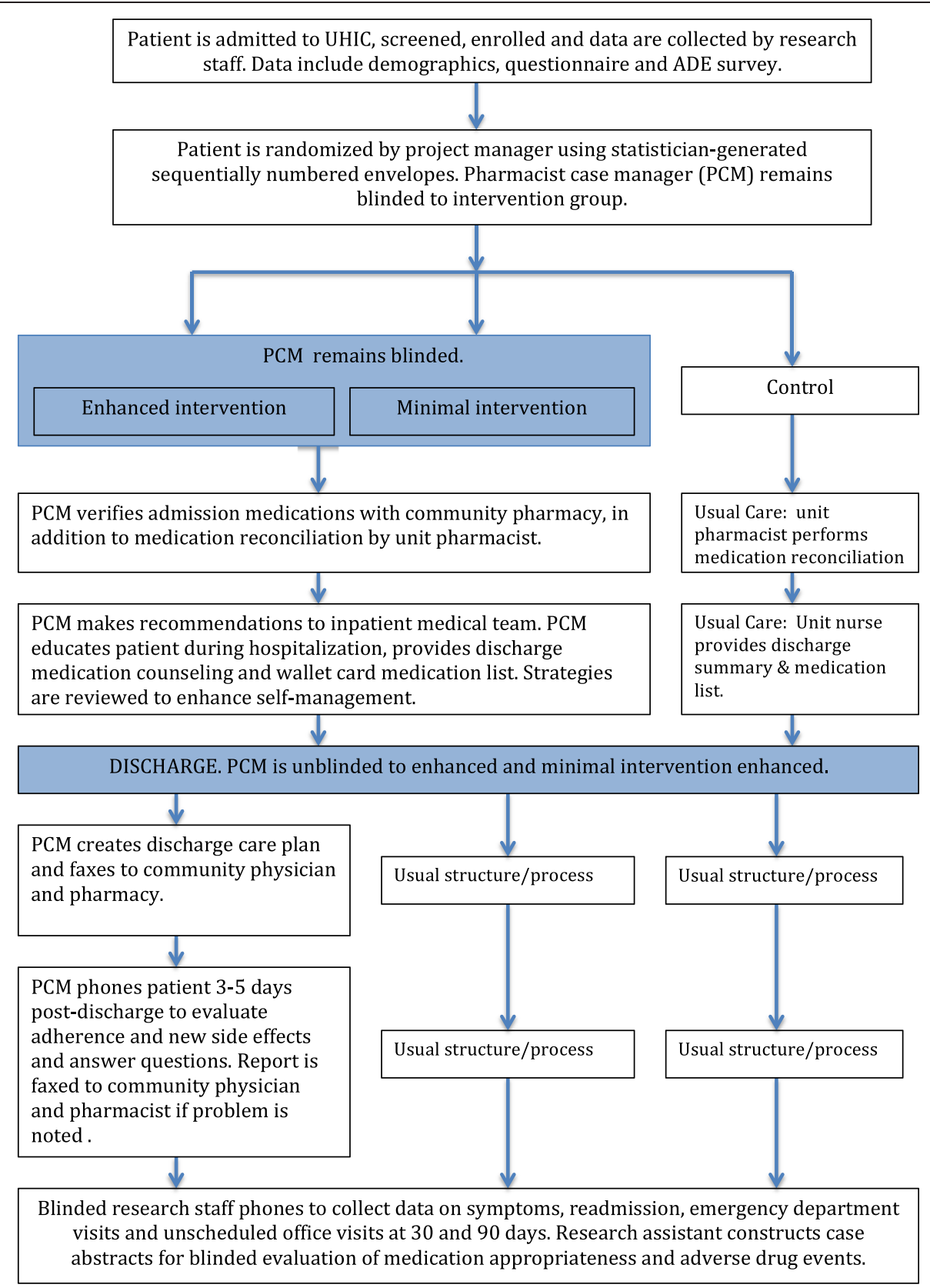

Figure 1 lowa Continuity of Care Recruitment and Intervention.

were either ineligible or lost to follow-up (Figure 2). We stopped the trial at 945 , as we had attained $95 \%$ of the intended participants and funding was nearing completion. The study was designed to have $80 \%$ power to detect a between-group effect size of 0.22 standard deviation for medication appropriateness.

\section{Intervention}

A pharmacist case manager (PCM) provided a set of specified activities for the minimal and enhanced intervention groups, as outlined in Figure 1 [12]. The PCMs were PharmD-trained with pharmacy residency training or equivalent direct patient care experience. Two investigators (BLC, AJC) trained two PCMs concerning the intervention, strategies to communicate with inpatient physicians, primary care physicians and community pharmacists and methods to improve medication adherence. Over time there was turnover in PCMs, so each new PCM was trained by the previous intervention pharmacists by providing care together for several study participants, with a focus on the intervention activities and study documentation. 


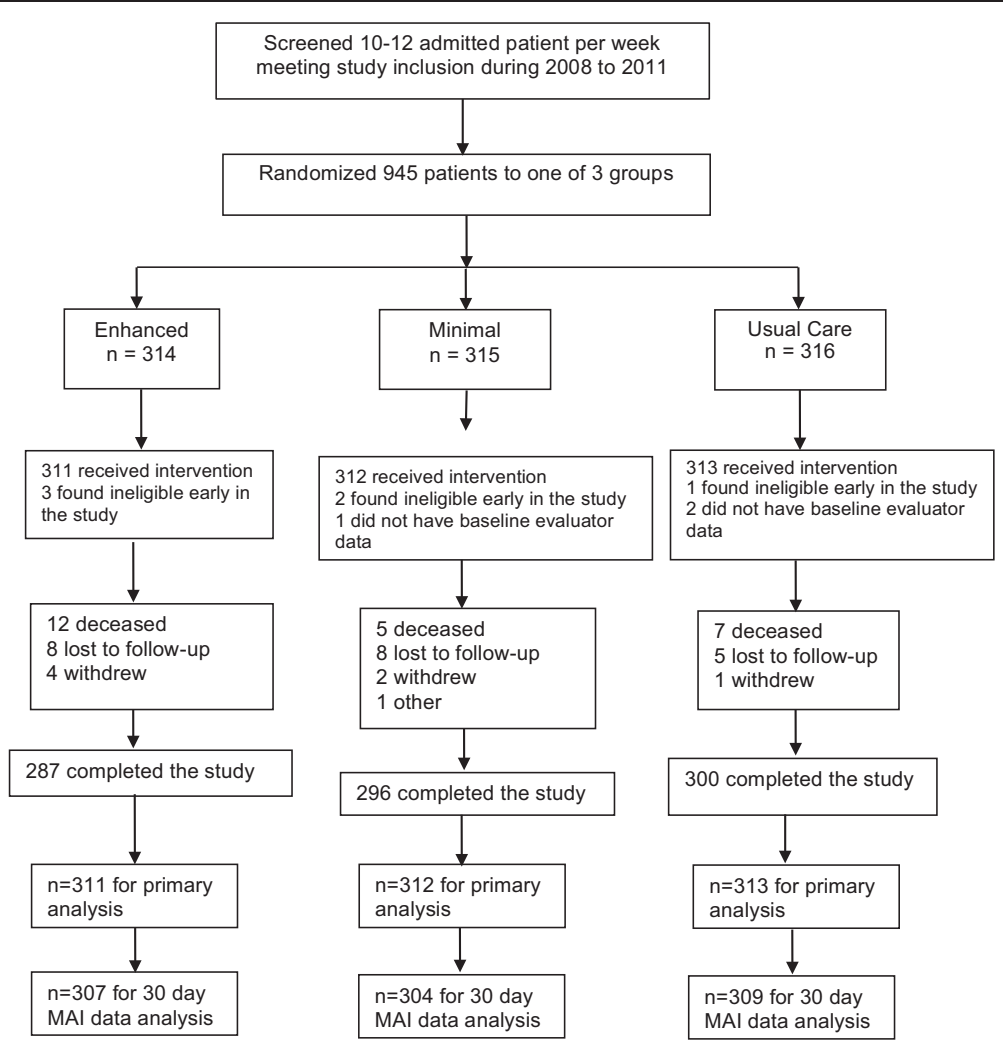

Figure 2 lowa Continuity of Care Study Recruitment Chart.

Participants in the minimal and enhanced intervention groups received admission medication reconciliation, pharmacist visits every 2-3 days for patient education during inpatient stay, discharge counseling and discharge medication list. For example, counseling was tailored for each participant and focused on goals of therapy, medication administration, barriers to adherence including cost and patient concerns [12]. Participants in the enhanced intervention group also received a telephone call at 3-5 days post-discharge and primary care physician and community pharmacist received a discharge care plan focused on medication changes and recommendations. The care plan was faxed to the primary care physician and community pharmacist within 24 hours of discharge but usually within 6 hours. The care plan included the discharge medication list, plans for dosage adjustments and monitoring, recommendations for preventing adverse drug events, with patientspecific concerns such as adherence or cost issues highlighted. Usual care was medication reconciliation at admission according to hospital policy, nurse discharge counseling and a discharge medication list for patients. The usual care discharge summary was transcribed and received in the mail by the primary care physician several days or weeks after discharge.

\section{Data collection}

The research assistant gathered baseline data including demographics, clinical characteristics and medicationrelated information [13-17]. The PCM recorded all interventions. At 30 and 90 days post-discharge, all participants were phoned by trained research assistants to gather self-reported adverse events and symptoms and selfreported healthcare utilization. Primary care provider and pharmacy records were obtained for all subjects. Hospitalization records were obtained from the university hospital and community hospitals when such an event occurred.

The primary outcome for the study was medication appropriateness. The medication appropriateness index (MAI) was completed by two trained research pharmacists (not the intervention pharmacists) who rated the appropriateness of all medications for all study subjects using medication lists at discharge, 30 days postdischarge and 90 days post-discharge [17]. These lists were obtained from community pharmacy and physician office records. Each medication was scored 0 for appropriate or somewhat appropriate, and 1 for inappropriate on each of six criteria. These six criteria (weight) included indication for medication (3), optimal medication (3), dose appropriate (2), drug-disease interaction (2), 
unnecessary duplication (1) and least expensive alternative (1). For each medication, the weighted sum across the six criteria were calculated, with an MAI range for each medication of $0=$ fully appropriate to 12 = fully inappropriate. We calculated the sum per patient and the average MAI per medication.

Secondary outcomes included adverse events (AEs), preventable adverse events and a composite variable of combined hospital readmission, emergency department visit or unscheduled office visit during the 30-day and 90-day follow-up period. We determined adverse events arising from lack of medications, either non-adherence or under-treatment, and adverse drug events arising from medication exposures $[18,19]$. The trained research pharmacists reviewed all records including hospital discharge summary, primary care records, pharmacy records and 30-day and 90-day telephone calls to identify symptomatology which we termed potential adverse events. The research pharmacists then rated four questions for each potential adverse event to determine the confidence that the symptoms arose from patient nonadherence, under-treatment or medication exposure and the final question asked about preventability. For medication exposure, a Naranjo score was calculated from ten items to determine the extent to which symptoms may be related to medications [20]. The research pharmacists' ratings to these questions were reviewed by a team of physician and pharmacist to confirm the ratings. In the analysis, only AEs or ADEs with virtual certainty or strong level of confidence or a Naranjo score of 5 or greater was counted. The number of AEs and ADEs for each subject was determined, and each AE and ADE was labeled as preventable if the preventability rating was definite or probable.

Finally, we counted the number of occurrences of hospital readmission, emergency department visits and unscheduled office visits using patient self-report and physician and hospital records.

\section{Analysis}

Descriptive statistics were calculated for the demographics, clinical characteristics and the study outcomes. The fidelity of pharmacist interventions was compared between minimal and enhanced groups using the chisquare test for categorical variables and t-tests for numeric variables. Preliminary analyses accommodating random effects due to pharmacists indicated very little, if any, clustering within pharmacist, so standard regression methods were used to analyze the study outcomes. For the case of MAI and MAI per medication, linear regression was performed on the square root scale to improve normality. The other outcomes were dichotomous and analyzed using logistic regression. Since the minimal and enhanced interventions were identical until patient discharge, comparisons were made with both intervention groups combined versus the control group at discharge. For post-discharge comparisons, each intervention group was compared to the control group. We performed a subgroup analysis including only those who had heart failure or asthma/pulmonary disease using the same analytic approach as described above.

\section{Results}

We enrolled 945 participants into the study (Figure 2), and study groups were comparable at baseline (Table 1). The mean age $( \pm \mathrm{SD})$ of participants in the study was 61.0 $( \pm 12.2)$ years, with $91 \%$ white and $66 \%$ married or living as married. The income and education distributions showed that $47 \%$ of study participants had an annual income less than $\$ 40,000$ and $49 \%$ had a high school education, respectively. Most participants in the study had health insurance, with almost half having private insurance. Almost all, 96\%, had prescription drug insurance.

Participants were similar in terms of chronic conditions, smoking status and alcohol intake at baseline, though baseline medications were slightly higher in the minimal intervention group compared to controls $(\mathrm{p}=0.0009)$ (Table 1). The prevalence of chronic kidney disease and reporting never or rarely forgetting to take medications did vary by study group. More participants in the control group $(85.6 \%)$ rarely forgot their medications compared to minimal $(79.0 \%)$ and enhanced $(75.2 \%)(p<0.0046)$. Selfrated health was comparable across the study groups, and $13 \%$ rated their health as poor, $27 \%$ as fair, $40 \%$ as good and $21 \%$ were very good or excellent.

Intervention fidelity was high for admission medication reconciliation and wallet card, but was variable for other parts of the intervention (Table 2). Discharge counseling was provided to $75 \%$ of enhanced and minimal intervention participants. Among the enhanced intervention group, $84 \%$ had their care plan faxed to their community physicians and $80 \%$ had it faxed to community pharmacists. Five pharmacists delivered the PCM activities over the study period, and their average time spent on study activities varied from $83( \pm 26)$ to $202( \pm 112)$ minutes per patient per pharmacist $(\mathrm{p}<0.0001)$. As expected, pharmacists spent considerably more time with enhanced versus minimal participants $(\mathrm{p}<0.0001)$.

The average MAI per medication as 0.53 at discharge and increased to 0.75 at 90 days, and this was true across all study groups (Table 3 ). There were no statistically significant differences in MAI supporting the intervention. The control group had a statistically significantly lower (improved) total MAI at discharge compared to minimal and enhanced groups, but the average MAI per medication was not different.

Post-discharge, about $16 \%$ of all participants experienced an $\mathrm{AE}$, and this did not differ by study group ( $\mathrm{p}>0.05)$ 
Table 1 Participant demographic and clinical characteristics

\begin{tabular}{|c|c|c|c|c|}
\hline & $\begin{array}{l}\text { Enhanced } \\
\mathrm{N}=311\end{array}$ & $\begin{array}{l}\text { Minimal } \\
\mathrm{N}=312\end{array}$ & $\begin{array}{l}\text { Control } \\
\mathrm{N}=313\end{array}$ & $\begin{array}{l}\text { Total } \\
(\mathrm{n}=936)\end{array}$ \\
\hline \multicolumn{5}{|l|}{ Age } \\
\hline$\leq 44$ years & $34(10.9)$ & $38(12.2)$ & $29(9.3)$ & $101(10.8)$ \\
\hline $45-54$ years & $43(13.8)$ & $52(16.7)$ & $49(15.7)$ & $144(15.4)$ \\
\hline $55-64$ years & $101(32.5)$ & $96(30.8)$ & $110(35.1)$ & $307(32.8)$ \\
\hline $65-74$ years & $85(27.3)$ & $85(27.2)$ & $85(27.2)$ & $255(27.2)$ \\
\hline$\geq 75$ years & $48(15.4)$ & $41(13.1)$ & $40(12.8)$ & $129(13.8)$ \\
\hline \multicolumn{5}{|l|}{ Education } \\
\hline Less than high school (1-8) & $16(5.1)$ & $12(3.9)$ & $22(7.0)$ & $50(5.3)$ \\
\hline High school (9-12) & $151(48.6)$ & $153(49.0)$ & $151(48.2)$ & $455(48.6)$ \\
\hline Some college & $66(21.2)$ & $73(23.4)$ & $59(18.9)$ & $198(21.2)$ \\
\hline College degree & $45(14.5)$ & $41(13.1)$ & $54(17.3)$ & $140(15.0)$ \\
\hline Professional or advanced degree & $33(10.6)$ & $33(10.6)$ & $27(8.6)$ & $93(9.9)$ \\
\hline \multicolumn{5}{|l|}{ Race } \\
\hline White & $287(92.3)$ & $283(90.7)$ & $285(91.1)$ & $855(91.4)$ \\
\hline African American & $12(3.9)$ & $16(5.1)$ & $18(5.8)$ & $46(4.9)$ \\
\hline Hispanic & $7(2.3)$ & $8(2.6)$ & $6(1.9)$ & $21(2.2)$ \\
\hline Other & $5(1.6)$ & $5(1.6)$ & $4(1.3)$ & $14(1.5)$ \\
\hline \multicolumn{5}{|l|}{ Annual income } \\
\hline$<\$ 10,000$ & $32(10.4)$ & $34(11.0)$ & $35(11.2)$ & $101(10.9)$ \\
\hline$\$ 10,000-\$ 24,999$ & $55(17.8)$ & $56(18.1)$ & $64(20.5)$ & $175(18.8)$ \\
\hline$\$ 25,000-\$ 39,999$ & $68(22.0)$ & $53(17.1)$ & $42(13.5)$ & $163(17.5)$ \\
\hline$\$ 40,000-\$ 54,999$ & $56(18.1)$ & $46(14.8)$ & $42(13.5)$ & $144(15.5)$ \\
\hline$\$ 55,000$ and greater & $98(31.7)$ & $121(39.0)$ & $129(41.4)$ & $348(37.4)$ \\
\hline Missing & 2 & 2 & 1 & 5 \\
\hline \multicolumn{5}{|l|}{ Marital status } \\
\hline Single/never married & $21(6.8)$ & $18(5.8)$ & $29(9.3)$ & $68(7.3)$ \\
\hline Married or living as married & $194(62.6)$ & $213(68.3)$ & $206(65.8)$ & $613(65.6)$ \\
\hline Divorced/separated & $56(18.1)$ & $49(15.7)$ & $51(16.3)$ & $156(16.7)$ \\
\hline Widowed & $39(12.6)$ & $32(10.3)$ & $27(8.6)$ & $98(10.5)$ \\
\hline \multicolumn{5}{|l|}{ Medical service } \\
\hline Internal Medicine/Family Medicine & $79(25.4)$ & $84(26.9)$ & $84(26.8)$ & $247(26.4)$ \\
\hline Cardiology & $111(35.7)$ & $111(35.6)$ & $112(35.8)$ & $334(35.7)$ \\
\hline Orthopedics & $121(38.9)$ & $117(37.5)$ & $117(37.4)$ & $355(37.9)$ \\
\hline \multicolumn{5}{|l|}{ Type of medical insurance } \\
\hline Private & $157(50.5)$ & $145(46.5)$ & $158(50.5)$ & $460(49.2)$ \\
\hline Medicare & $120(38.6)$ & $123(39.2)$ & $114(36.4)$ & $357(38.1)$ \\
\hline Medicaid & $27(8.7)$ & $39(12.5)$ & $38(12.1)$ & $104(11.1)$ \\
\hline Other insurer/none/self-pay & $7(2.3)$ & $5(1.6)$ & $3(1.0)$ & $15(1.6)$ \\
\hline \multicolumn{5}{|l|}{ Prescription drug insurance } \\
\hline Yes & $297(95.5)$ & $294(94.5)$ & $303(97.1)$ & $894(95.7)$ \\
\hline Average number of prescription medications* & $11.0(5.7)$ & $11.8(6.0)$ & $10.4(5.5)$ & $11.0(5.8)$ \\
\hline
\end{tabular}


Table 1 Participant demographic and clinical characteristics (Continued)

Chronic conditions (\% yes)

Hypertension
Hyperlipidemia
Heart failure
Coronary artery disease
Myocardial infarction
Transient ischemic attacks
Stroke
Depression
Anxiety
Arthritis
Diabetes
Kidney disease*
Liver disease
Asthma or pulmonary disease
Knee replacement
Hip replacement
Fracture
Cancer
Other

\section{Smoking status}

Never

$249(80.1)$

$231(74.0)$

$239(76.4)$

$719(76.8)$

$194(62.4)$

$195(62.5)$

$189(60.3)$

$578(61.8)$

$85(27.3)$

$91(29.2)$

$76(24.3)$

$252(26.9)$

$114(36.7)$

108 (34.6)

94 (30.0)

316 (33.8)

$69(22.2)$

$68(21.8)$

$62(19.8)$

$199(21.2)$

26 (8.4)

30 (9.6)

$26(8.3)$

$82(8.8)$

$12(3.9)$

$17(5.5)$

$14(4.5)$

$43(4.6)$

105 (33.8)

105 (33.7)

98 (31.3)

308 (32.9)

91 (29.3)

79 (25.3)

73 (23.3)

$243(26.0)$

193 (62.1)

197 (63.1)

192 (61.3)

582 (62.2)

$113(36.3)$

$123(39.4)$

$114(36.4)$

350 (37.4)

35 (11.3)

58 (18.6)

15 (4.8)

$17(5.5)$

34 (10.9)

127 (13.6)

79 (25.4)

$14(4.5)$

$46(4.9)$

82 (26.4)

90 (28.9)

86 (27.5)

255 (27.2)

49 (15.8)

70 (22.4)

78 (24.9)

$230(24.6)$

135 (43.4)

$36(11.5)$

$32(10.2)$

$117(12.5)$

56 (18.0)

$133(42.6)$

$131(41.9)$

399 (42.6)

172 (55.3)

54 (17.3)

49 (15.7)

159 (17.0)

$183(58.7)$

171 (54.6)

$526(56.2)$

Current

132 (42.4)

150 (48.1)

$126(40.3)$

408 (43.6)

33 (10.6)

35 (11.2)

Ex-smoker

$146(47.0)$

127 (40.7)

$27(8.6)$

95 (10.2)

Alcohol intake

None

$200(64.3)$

190 (60.9)

$160(51.1)$

$433(46.3)$

$<1$ drink/day

$82(26.4)$

183 (58.7)

573 (61.3)

1-2 drinks/day

$22(7.1)$

95 (30.5)

$100(32.1)$

277 (29.6)

$\geq 3$ drinks/day

7 (2.3)

$21(6.7)$

6 (1.9)

24 (7.7)

$67(7.2)$

Self-rated health

Excellent

15 (4.8)

Very good

Good

Fair

Poor

Self-reported medication adherence

Forget (\% never or rarely)*

Careless (\% never or rarely)

Stop if feel better (\% never or rarely)

Stop if feel worse (\% never or rarely)

\section{Medication management ability}

Able (\% scoring 5)

Some limitation (\% 4 or less)

Missing
$55(17.7)$

$116(37.4)$

88 (28.4)

$36(11.6)$

$233(75.2)$

$282(91.0)$

$292(94.2)$

278 (89.7)

$203(66.3)$

103 (33.7)

5

\section{3 (4.2)}

44 (14.1)

122 (39.1)

87 (27.9)

46 (14.7)

$245(79.0)$

289 (93.2)

$292(94.2)$

278 (89.7)

218 (70.1)

93 (29.9)

1

5 (1.6)

$18(1.9)$

19 (6.1)

$47(5.0)$

48 (15.3)

147 (15.7)

$132(42.2)$

370 (39.6)

79 (25.2)

254 (27.2)

35 (11.2)

117 (12.5)

267 (85.6)

745 (79.9)

299 (95.8)

870 (93.4)

302 (96.8)

886 (95.1)

286 (91.7)

$842(90.3)$

$211(68.5)$

632 (68.3)

97 (31.5)

293 (68.3) 
Table 1 Participant demographic and clinical characteristics (Continued)

\begin{tabular}{|c|c|c|c|c|}
\hline \multicolumn{5}{|l|}{ Medication self-efficacy scale } \\
\hline Average (standard deviation) & $123.3( \pm 12.5)$ & $124.4( \pm 12.3)$ & $125.0( \pm 10.1)$ & $124.2( \pm 11.7)$ \\
\hline \multicolumn{5}{|l|}{ Instrumental activities of daily living } \\
\hline No limitation & $215(69.4)$ & $226(72.4)$ & $239(76.4)$ & $680(72.7)$ \\
\hline Requires help or unable on 1 & $35(11.3)$ & $42(13.5)$ & $27(8.6)$ & $104(6.0)$ \\
\hline Requires help or unable on 2 & $22(7.1)$ & $13(4.2)$ & $21(6.7)$ & $56(6.0)$ \\
\hline Requires help or unable on 3 or more & $38(12.2)$ & $31(9.9)$ & $26(8.3)$ & $95(10.1)$ \\
\hline
\end{tabular}

*Variables were significantly different among groups $(p<0.01)$.

Table 2 Fidelity of pharmacists' interventions

\begin{tabular}{|c|c|c|c|}
\hline & $\begin{array}{l}\text { Enhanced } \\
\mathrm{n}=311\end{array}$ & $\begin{array}{l}\text { Minimal } \\
\mathrm{n}=312\end{array}$ & P-values \\
\hline Admission medication reconciliation & $311(100 \%)$ & $312(100 \%)$ & \\
\hline Community pharmacy contacted & $300(96.5 \%)$ & $305(97.8 \%)$ & 0.34 \\
\hline Discharge counseling completed & $235(75.6 \%)$ & $235(75.3 \%)$ & 0.94 \\
\hline Wallet card completed & $309(99.4 \%)$ & $308(98.7 \%)$ & 0.41 \\
\hline Medication issues identified in hospital & $275(88.4 \%)$ & $249(79.8 \%)$ & 0.003 \\
\hline Post-discharge phone call completed & $301(96.8 \%)$ & $4(1.3 \%)^{*}$ & \\
\hline Discharge care plan faxed to community physician & $267(85.9 \%)$ & $1(0.3 \%)^{*}$ & \\
\hline Discharge care plan faxed to community pharmacist & $246(79.1 \%)$ & $1(0.3 \%)^{*}$ & \\
\hline $\begin{array}{l}\text { Discharge care plan included medication recommendations to community } \\
\text { physician }\end{array}$ & $207(66.6 \%)$ & NA & \\
\hline Discharge care plan medication issues identified by pharmacists & $\begin{array}{l}\text { To Hospital \& Community } \\
\text { Physicians }\end{array}$ & $\begin{array}{l}\text { To Hospital } \\
\text { Physicians }\end{array}$ & \\
\hline Mean $( \pm S D)$ & $6.6( \pm 6.8)$ & $3.2( \pm 4.0)$ & \\
\hline Total number of issues identified & 2063 & 1012 & \\
\hline Dosing or administration & 260 & 131 & \\
\hline Indication & 754 & 363 & \\
\hline Efficacy & 319 & 101 & \\
\hline Cost & 103 & 38 & \\
\hline Risk to patient & 627 & 379 & \\
\hline Discharge care plan recommendations made to physicianst & $\begin{array}{l}\text { To Hospital \& Community } \\
\text { Physicians }\end{array}$ & $\begin{array}{l}\text { To Hospital } \\
\text { Physicians }\end{array}$ & \\
\hline Mean $( \pm \mathrm{SD})$ & $7.1( \pm 6.6)$ & $3.5( \pm 3.8)$ & \\
\hline Total number of recommendations & 2220 & 1077 & \\
\hline Discontinue medications & 377 & 195 & \\
\hline Add medications & 566 & 256 & \\
\hline Change medications & 361 & 151 & \\
\hline Disease monitoring & 280 & 56 & \\
\hline Follow-up patient & 262 & 134 & \\
\hline Patient education & 283 & 239 & \\
\hline Adherence education & 91 & 46 & \\
\hline Time pharmacist spent on each patient (minutes) & $210.0( \pm 93.0)$ & $118.5( \pm 58.6)$ & $<.0001$ \\
\hline
\end{tabular}

*Inadvertent crossover since care plans should not have been sent according to randomization.

tMany but not all medication issues and recommendations were repeated to the community physicians, accounting for almost twice the numbers in the enhanced group. 
Table 3 Medication Appropriateness Index (MAI) by study group

\begin{tabular}{|c|c|c|c|c|}
\hline & Enhanced & Minimal & Control & P-values ${ }^{*}$ \\
\hline \multicolumn{5}{|c|}{ Summed MAI per Participant } \\
\hline Discharge & $7.1( \pm 7.0)$ & $8.0( \pm 8.4)$ & $6.1( \pm 6.6)$ & $E+M$ vs. C: 0.03 \\
\hline \multirow[t]{2}{*}{30 days post-discharge } & $10.1( \pm 8.9)$ & $11.7( \pm 11.2)$ & $9.6( \pm 9.5)$ & E vs. C: 0.78 \\
\hline & & & & M vs. C: 0.07 \\
\hline \multirow[t]{2}{*}{90 days post-discharge } & $11.6( \pm 10.5)$ & $13.6( \pm 12.3)$ & $11.1( \pm 11.3)$ & E vs. C: 0.94 \\
\hline & & & & M vs. C: 0.02 \\
\hline \multicolumn{5}{|l|}{ MAI per Medication } \\
\hline Discharge & $0.52( \pm 0.53)$ & $0.55( \pm 0.57)$ & $0.51( \pm 0.54)$ & $E+M$ vs. C: 0.26 \\
\hline \multirow[t]{2}{*}{30 days post-discharge } & $0.62( \pm 0.50)$ & $0.69( \pm 0.61)$ & $0.65( \pm 0.57)$ & E vs. C: 0.86 \\
\hline & & & & M vs. C: 0.70 \\
\hline \multirow[t]{2}{*}{90 days post-discharge } & $0.72( \pm 0.68)$ & $0.80( \pm 0.65)$ & $0.73( \pm 0.63)$ & E vs. C: 0.84 \\
\hline & & & & M vs. C: 0.33 \\
\hline
\end{tabular}

${ }^{*} \mathrm{E}=$ enhanced, $\mathrm{M}=$ minimal and $\mathrm{C}=$ control groups.

(Table 4). The enhanced (6.1\%) and minimal (6.1\%) groups had more AE and ADEs during hospitalization identified than controls (4.5\%), but the difference was not statistically significant.

About 29\% of all participants had any type of healthcare utilization within 30 days post-discharge, where $15 \%$ of all participants had a 30 -day readmission. There were no statistically significant differences by study group for any utilization outcomes (Table 5). We examined the study participants with CHF and/or asthma/ COPD separately, and the results were consistent with our overall findings (data not shown).

\section{Discussion}

The pharmacist case manager did not affect medication appropriateness, number of clinically-relevant adverse events or adverse drug events or post-discharge healthcare utilization. These findings might be explained by the overall good medication appropriateness and generally low re-hospitalizations, ED visits and unscheduled office visits in all study groups when compared to previous studies. Other studies that have evaluated PCMs had mixed results, but our methodology and measures were anticipated to be sensitive to the intervention given previous findings about pharmacists' impact post-discharge [10]. Our finding is important given our strong study design, subjects with high medication use and a comprehensive assessment of all study outcomes.

Our primary outcome was medication appropriateness and we had good power to detect meaningful differences based on prior studies (17). Our study was powered to detect effect sizes of 0.22 in the MAI, but the largest effect size seen was 0.21 for minimal vs. control at 90 days, and this was in the wrong direction (minimal having a higher value). Moreover, the MAI per medication ranged from 0.51 to 0.8 , indicating high medication appropriateness across the study. These finding suggest very good medication appropriateness with limited opportunity for improvement regardless of the intervention.

Our process to determine adverse events and adverse drug events was comprehensive using patient self-report of symptomatology along with patient medical records and expert opinion to establish attribution [18-20]. Forster and colleagues evaluated ADEs after discharge [21]. Of 400 patients, 45 (11\%) had an ADE and over half could have been prevented or ameliorated. These ADEs occurred in spite of electronic discharge summaries being transmitted to primary care physicians. In our study, about $16 \%$ of all participants experienced an adverse event within the 90-day post-discharge period that was virtually certain or highly likely attributed to medications. While an interim analysis showed that medication discrepancies were reduced in the enhanced group, and the medication list in the primary care physician office was more likely to be up-to-date compared to the minimal or control groups [22], this finding did not translate into other findings.

Between 2008 and 2010 the readmission at the study hospital were 18.2 and $19.1 \%$, respectively, when our study was conducted [23]. However, the 30-day readmission rate among study participants ranged from $13.4 \%$ to $16.7 \%$, which is lower than anticipated when the study was designed. These observations would suggest that the rate of re-hospitalizations had dropped substantially after the study was designed which made it difficult for the intervention to improve these rates. There is conflicting evidence from other studies whether 30-day readmission rates were declining overall during our study period 2007-2012. Findings in the Veterans Affairs institutions suggest a decreasing trend over the past decade, 
Table 4 Adverse Events (AE) from non-adherence and under-treatment and Adverse Drug Events (ADE) by study group

\begin{tabular}{|c|c|c|c|c|}
\hline & Enhanced & Minimal & Control & P-values ${ }^{*}$ \\
\hline Initial Hospitalization & $\mathrm{n}=311$ & $n=312$ & $n=313$ & \\
\hline Number of possible adverse events & 40 & 43 & 40 & \\
\hline Number of AEs due to medication non-adherencet & 9 & 9 & 6 & \\
\hline Number of AEs due to medication under-treatment $†$ & 1 & 3 & 3 & \\
\hline Number of ADEst & 15 & 16 & 15 & \\
\hline Percent of participants with any AE or ADE $\dagger$ & $18(5.8 \%)$ & $19(6.1 \%)$ & $22(7.0 \%)$ & $E+M$ vs. C: 0.52 \\
\hline \multicolumn{5}{|l|}{ During Hospitalization } \\
\hline Number of possible adverse events & 55 & 52 & 57 & \\
\hline Number of AEs due to medication non-adherence $\dagger$ & 1 & 2 & 0 & \\
\hline Number of preventable medication non-adherence AEsł & 1 & 2 & 0 & \\
\hline Number of AEs due to medication under-treatment $\dagger$ & 2 & 0 & 1 & \\
\hline Number of preventable medication under-treatment AEs $\ddagger$ & 2 & 0 & 1 & \\
\hline Number of ADEst & 18 & 27 & 16 & \\
\hline Number of preventable ADEsł & 0 & 3 & 1 & \\
\hline Percent of participants with any AE or ADE $†$ & $19(6.1 \%)$ & $19(6.1 \%)$ & $14(4.5 \%)$ & $E+M$ vs. C: 0.31 \\
\hline Post-Discharge & $n=306$ & $n=309$ & $n=311$ & \\
\hline Number of possible adverse events & 183 & 180 & 174 & \\
\hline Number of AEs due to medication non-adherencet & 15 & 8 & 10 & \\
\hline Number of preventable medication non-adherence AEsł & 15 & 7 & 9 & \\
\hline Number of AEs due to medication under-treatment $\dagger$ & 10 & 13 & 6 & \\
\hline Number of preventable medication under-treatment AEsł & 6 & 11 & 5 & \\
\hline Number of ADEst & 47 & 49 & 60 & \\
\hline Number of preventable ADEsł & 8 & 7 & 9 & \\
\hline \multirow[t]{2}{*}{ Percent of participants with any AE or ADE $†$} & $48(15.7 \%)$ & $50(16.2 \%)$ & $53(17.0 \%)$ & E vs. C: 0.72 \\
\hline & & & & M vs. C: 0.95 \\
\hline
\end{tabular}

${ }^{*} \mathrm{E}=$ enhanced, $\mathrm{M}=$ minimal and $\mathrm{C}=$ control groups.

† Medication non-adherence and under-treatment were labeled adverse events (AEs) and counted only if the rating was "Virtually certain" or "Strong level of confidence". ADEs were counted only if the Naranjo score was 5 or greater.

¥AEs and ADEs were considered preventable if the rating was "Definitely preventable" or "Probably preventable".

but rates were steady for Medicare fee-for-service beneficiaries from 2007 through 2011, until 2012 when rates declined [23-25]. Focusing this intervention exclusively on individuals with high risk for readmission postdischarge would have been a better strategy, yet our subanalysis for heart failure showed no differences. Finally, a broader view of health and functional status besides medications is likely necessary to further reduce readmissions. For example, medications are one component of the Care Transitions Intervention, but it is not the solitary focus [26].

The content of the PCM intervention was multi-faceted not merely medication reconciliation. There was some variability in the delivery of the intervention by the PCMs, but almost all participants were provided a medication reconciliation at admission and discharged medication lists. The PCM was expected to improve medication use at discharge via medication reconciliation and recommendations to the inpatient team. During study initiation, policy changed at the study hospital and many usual care patients received admission medication reconciliation. While the PCM contacted the community pharmacist for almost all participants at baseline in the minimal and enhanced groups, we cannot establish the effect of this call. As well, the discharge care plan was faxed to $86 \%$ of participants' community physicians, and only $66 \%$ contained specific medication recommendations. These two facets of the intervention may have reduced its effectiveness.

Numerous studies have shown a positive impact of pharmacists' recommendations when they work directly with teams [27-34]. In considering the lack of effect at discharge, the PCMs were study pharmacists and not part of the inpatient medical teams. Our interim analysis showed that about half of the pharmacists' recommendations were 
Table 5 Hospital readmission, emergency department visits or unscheduled office visits by study group

\begin{tabular}{|c|c|c|c|c|}
\hline & Enhanced & Minimal & Control & *P-values \\
\hline \multicolumn{5}{|c|}{ Number of patients with any post-discharge healthcare use } \\
\hline \multirow[t]{2}{*}{30 days } & $81(28.8 \%)$ & $88(29.5 \%)$ & $87(29.6 \%)$ & E vs. C: 0.82 \\
\hline & & & & M vs C: 0.92 \\
\hline \multirow[t]{2}{*}{90 days } & $97(34.5 \%)$ & $90(30.5 \%)$ & $88(29.9 \%)$ & E vs. C: 0.20 \\
\hline & & & & M vs C: 0.62 \\
\hline \multicolumn{5}{|c|}{ Number of patients with at least one specific post-discharge healthcare use } \\
\hline \multirow[t]{2}{*}{30 day readmission } & $47(16.7 \%)$ & $40(13.4 \%)$ & $43(14.6 \%)$ & E vs. C: 0.29 \\
\hline & & & & M vs C: 0.38 \\
\hline \multirow[t]{2}{*}{30 day emergency dept visit } & $38(13.5 \%)$ & $49(16.5 \%)$ & $52(17.8 \%)$ & E vs. C: 0.18 \\
\hline & & & & M vs C: 0.71 \\
\hline \multirow[t]{2}{*}{30 day unscheduled visit } & $31(11.0 \%)$ & $30(10.1 \%)$ & $32(10.9 \%)$ & E vs. C: 0.81 \\
\hline & & & & M vs C: 0.69 \\
\hline \multirow[t]{2}{*}{90 day readmission } & 49 (17.4\%) & $51(17.3 \%)$ & $47(16.0 \%)$ & E vs. C: 0.77 \\
\hline & & & & M vs C: 0.83 \\
\hline \multirow[t]{2}{*}{90 day emergency dept visit } & $41(14.6 \%)$ & $40(13.6 \%)$ & $46(15.7 \%)$ & E vs. C: 0.99 \\
\hline & & & & M vs C: 0.54 \\
\hline \multirow[t]{2}{*}{90 day unscheduled visit } & $42(15.0 \%)$ & $36(12.2 \%)$ & $33(11.3 \%)$ & E vs. C: 0.18 \\
\hline & & & & M vs C: 0.74 \\
\hline
\end{tabular}

${ }^{*} \mathrm{E}=$ enhanced, $\mathrm{M}=$ minimal and $\mathrm{C}=$ control groups.

accepted by hospitalists or physicians in the in-patient setting [35] and the recommendations did not change the prescribing of cardiovascular medications [36]. Anecdotally, inpatient physicians often were reluctant to accept recommendations for chronic conditions, e.g. hyperlipidemia or diabetes, when these were not the reason for the hospitalization. These findings were disappointing, and the low rate of accepted recommendations is counter to pharmacists' contribution to improved outcomes in both inpatient and primary care settings [27-34].

The medication care plan and the 3-5 day post-discharge telephone call were expected to have an impact postdischarge. About $86 \%$ of participants had the discharge care plan faxed to physicians and almost all participants in the enhanced intervention group received the post-discharge telephone follow-up. While over 2000 recommendations were in the care plans, about one-half of these were provided to community physicians. Many of the recommendations were related to adding, changing or discontinuing medications. Physicians in the community may have not been aware of the hospitalization until a follow-up visit was done post-discharge. At that time, a discharge summary and/or the medication care plan could have been reviewed, but we have no conclusive way to know whether that occurred. There was no verbal hand-off back to the community providers. The development of a discharge medication care plan and sharing the care plan with physicians via fax were insufficient to improve medication use or patient outcomes. A verbal hand-off to physicians was effective in two previous studies, suggesting this contact may be critical $[37,38]$. However, the best time to actually complete the verbal hand-off to the primary care physician is unclear, as the timing would likely be best when the provider is scheduled to see the discharged patient. Further, the telephone follow-up, although provided to almost all intended participants at 3-5 days post-discharge, was not sufficient to improve outcomes for this population.

Finally, the study population was younger than many other studies where care transition programs have been effective [9,26]. Many of the individuals may not have had a high enough acuity to require such support during their transition, as about $70 \%$ had no instrumental activity of daily living limitation, only $40 \%$ rated their health as fair or poor, few reported intentional medication nonadherence, 25\% reported forgetting medications and most participants had high medication self-efficacy. In retrospect, we should have focused this care transition intervention towards individuals with transition issues rather than those where pharmacists had been successful impacting outcomes in previous studies. In consideration of other studies and our current findings, we suggest that medication-focused care transition activities be targeted to individuals with greater health acuity who are known to exhibit medication management difficulties. In addition, implementation of medication-related recommendations will require more intense interventions than fax from the tertiary hospital with the primary care physicians after discharge. 
This study has implications for policies related to reducing hospital readmissions. Hospitals will need to evaluate the most efficient and effective methods to reduce readmissions and reduce adverse events. Improved information technology may be useful in transmitting discharge care plan information more efficiently, but it appears likely that a verbal or electronically verified hand-off may be necessary $[37,38]$. Such an approach would help ensure that important issues requiring follow-up were specifically identified for community providers. However, the most effective strategy may be stronger relationships and communications with care navigators or primary care physicians to optimize medications since it is hospitals that are at risk for re-admissions.

This study has limitations. At baseline, forgetting medications was not well randomized. Yet, it is unlikely that this single aspect of medication management would change the impact of the intervention on medication appropriateness or adverse events to a great degree across the three study groups. The intervention fidelity was good but not without some issues. We cannot separate the effect of any specific component of the intervention such as patient counseling on the outcomes of the study. We failed to determine whether community physicians actually used the discharge medication care plan information that was sent, and this is an important missing link in the process of care and in this study. As well, factors such as pharmacist personalities and health-system relationships with non-health system primary care providers form an important context in which such studies are completed and these cannot be ignored when considering generalizability. We did not separate self-reported versus medically document post-discharge events, which may contribute to measurement error making it more difficult to detect an effect.

\section{Conclusions}

In conclusion, a pharmacist case manager providing admission medication reconciliation, in-patient medication recommendations to the hospital team, patient education, post-discharge information to community physicians and post-discharge telephone call to patients did not affect medication appropriateness, adverse events or post-discharge healthcare utilization.

\footnotetext{
Abbreviations

PCM: Pharmacist case manager; ADE: Adverse drug event; UIHC: University of lowa Hospitals and Clinics; MAl: Medication appropriateness index; AE: Adverse event; SD: Standard deviation.

\section{Competing interests}

All of the authors had full access to all of the data in the study and take responsibility for the integrity of the data and the accuracy of the data analysis.

Karen Farris

- Consultant for $£ 1000$ to London School of Economics and Political Sciences about the role of pharmacists in the United States
}

- Honoraria and travel expenses from Eli Lilly and Company in 2010 for presentation and article about pharmacists in care transitions Barry Carter

- Consultant for Pro-Vice Chancellor for Research, Queens University, Centre on Health Improvement, Belfast, Northern Ireland, May 2010 about pharmacists' roles.

The other authors no had conflicts to declare.

\section{Authors' contributions}

$\mathrm{KF}, \mathrm{BC}, \mathrm{DW}, \mathrm{PK}, \mathrm{PJ}, \mathrm{AC}$ and $\mathrm{JB}$ were involved in the design and execution of the study. KF and CS were responsible for the day-to-day activities. YX was responsible for data management and $Y X$ and JD conducted the statistical analyses. BC, DW, PK and PJ assessed the adverse drug events. All authors reviewed the drafts of the manuscripts and approved the final version.

\section{Acknowledgements}

Contributors. NA.

Funders. This study was supported by the National Heart, Lung, and Blood Institute (1RO1 HL082711). Drs. Carter, Kaboli and Christensen are also supported by the Comprehensive Access and Delivery Research and Evaluation (CADRE), Department of Veterans Affairs, Veterans Health Administration, Health Services Research and Development Service (HFP 04-149). The views expressed in this article are those of the authors and do not necessarily reflect the position or policy of the Department of Veterans Affairs. Prior presentations. NA.

Drs. Farris and Carter had full access to all of the data in the study and take responsibility for the integrity of the data and the accuracy of the data analysis.

\section{Author details}

${ }^{1}$ College of Pharmacy, University of Michigan, 428 Church St, Ann Arbor, MI 48109-1065, USA. ²Department of Pharmacy Practice and Science, College of Pharmacy, University of lowa, lowa City, IA, USA. ${ }^{3}$ Department of Family Medicine, Carver College of Medicine, University of lowa, lowa City, IA, USA. ${ }^{4}$ Department of Biostatistics, College of Public Health, University of lowa, lowa City, IA, USA. ${ }^{5}$ Department of Pharmaceutical Care, University of lowa Hospital and Clinics, Iowa City, IA, USA. 'Department of Internal Medicine, Carver College of Medicine, University of lowa, lowa City, IA, USA. ${ }^{7}$ lowa City Veterans Affairs Health Care System, lowa City, IA, USA. ${ }^{8}$ Department of Psychology, University of lowa, lowa City, IA, USA. ${ }^{9}$ College of Pharmacy, University of South Carolina, Columbia, SC, USA.

Received: 24 April 2014 Accepted: 10 September 2014 Published: 18 September 2014

\section{References}

1. Coleman EA, Smith JK, Raha D, Min SJ: Post-hospital medication discrepancies: prevalence and contributing factors. Arch Intern Med 2005, 165:1842-1847.

2. Kripalani S, Jackson AT, Schnipper $J$, Coleman EA: Promoting effective transitions of care at hospital discharge: a review of key issues for hospitalists. J Hosp Med 2007, 2:314-323.

3. Bayoumi I, Howrd M, Holbrook AM, Schabort I: Interventions to improve medication reconciliation in primary care. Ann Pharmacother 2009, 43:1667-1675

4. Flora DS, Parsons PL, Slattum PW: Managing medications for improved care transitions. Generations 2011, 35:37-42.

5. Ziaeian B, Araujo K, Van Ness PH, Horwitz LI: Medication reconciliation accuracy and patient understanding of intended medication changes on hospital discharge. J Gen Intern Med 2012, 27:1513-1520.

6. American Society of Health-system Pharmacists and American Pharmacists Association: ASHP-APhA medication management in care transitions best practices. http://media.pharmacist.com/practice/ASHP_APhA_ MedicationManagementinCareTransitionsBestPracticesReport2_2013.pdf, Accessed September 22, 2014.

7. Kwan JA, Lo L, Sampson M, Shojania K: Medication reconciliation during transitions of care as a patient safety strategy: a systematic review. Ann Intern Med 2013, 158:397-403.

8. Mueller SK, Sponsler KC, Kriplani S, Schnipper JL: Hospital-based medication reconciliation practices: a systematic review. Arch Intern Med 2012, 172:1057-1069. 
9. Hesselink G, Schoonhoven L, Barach P, Spijker A, Gademan P, Kalkman C, Liefers J, Vernooij-Dassen M, Wollersheim H: Improving patients handovers form hospital to primary care: a systematic review. Ann Intern Med 2012, 157:417-428.

10. Schnipper JL, Kirwin $J$, Cotugno MC, Wahlstrom SA, Brown BA, Tarvin E, Kachalia A, Horng M, Roy CL, McKean SC, Bates DW: Role of pharmacist counseling in preventing adverse drug events after hospitalization. Arch Intern Med 2006, 166:565-571.

11. Institute for Healthcare Improvement: Medication reconciliation to prevent adverse events. http://www.ihi.org/explore/adesmedicationreconciliation/ Pages/default.aspx, Accessed September 22, 2014.

12. Carter BL, Farris KB, Abramowitz PW, Weetman DB, Kaboli PJ, Dawson JD, James PA, Christensen AJ, Brooks JM: The lowa continuity of care study: background and methods. Am J Health-Syst Pharm 2008, 65:1631-1642.

13. Katz $S$, Akpom CA: A measure of primary sociobiological functions. Int J Health Serv 1976, 6:493-508.

14. Ruscin JM, Semla TP: Assessment of medication management skills in older outpatients. Ann Pharmacother 1996, 30:1083-1088.

15. Morisky DE, Green LW, Levine DM: Concurrent and predictive validity of a self-reported measure of medication adherence. Med Care 1986, 24:67-74

16. DeGeest S, Abraham I, Gemoets H, Evers G: Development of the long-term medication behavior self-efficacy scale: qualitative study for item development. J Adv Nurs 1994, 19:233-238.

17. Hanlon JT, Schmader KE, Samsa GP, Weinberger M, Uttech KM, Lewis IK, Cohen HJ, Feussner JR: A method for assessing drug therapy appropriateness. J Clin Epidemiol 1992, 45:1045-1051.

18. Bates DW, Cullen DJ, Laird N, Peterson LA, Small SD, Servi D, Laffel G, Sweitzer BJ, Shea BF, Hallisey R, Vander Vliet M, Nemeskal R, Leape LL, for the ADE Prevention Study Group: Incidence of adverse drug events and potential adverse drug events. Implications for prevention. ADE Prevention Study Group. JAMA 1995, 274:29-34.

19. Gandhi TK, Weingart SN, Borus J, Seger AC, Peterson J, Burdick E, Seger DL, Shu K, Federico F, Leape LL, Bates DW: Adverse drug events in ambulatory care. N Engl J Med 2003, 348:1556-1564.

20. Naranjo CA, Busto U, Sellers EM, Sandor P, Ruiz I, Roberts EA, Janecek E, Comecq C, Greenblatt DJ: A method for estimating the probability of adverse drug reactions. Clin Pharmacol Ther 1981, 30:239-245.

21. Forster AJ, Murff JH, Peterson JF, Gandhi TK, Bates DW: Adverse drug events occurring following hospital discharge. J Gen Intern Med 2005, 20:317-323.

22. Farley TM, Shelsky C, Powell S, Farris KB, Carter BL: Effect of clinical pharmacist intervention on medication discrepancies following hospital discharge. Int J Clin Pharm 2014, 36:430-437.

23. Dartmouth Atlas of Health Care: http://www.dartmouthatlas.org/data/table. aspx?ind=192, Accessed September 22, 2014

24. Kaboli PJ, Go J, Hockenberry J, Glasgow JM, Johnson SR, Rosenthal GE, Jones MP, Vaughan-Sarrazin M: Association between reduced hospital length of stay and 30-day readmission rate and mortality: 14-year experience in 129 Veterans Affairs hospitals. Ann Intern Med 2012, 157:837-845.

25. Gerhardt G, Yemane A, Hickman P, Oelschlaeger A, Rollins E, Brennan N: Medicare readmission rates showed meaningful decline in 2012. MMRR 2013, 3:2

26. Parry C, Coleman EA, Smith JD, Frank JC, Kramer AM: The care transitions intervention: a patient-centered approach to facilitating effective transfers between sites of geriatric care. Home Health Serv Q 2003, 22(3):1-18.

27. Kaboli PJ, Hoth AB, McCLimon BJ, Schnipper JL: Clinical pharmacists and inpatient medical care: a systematic review. Arch Intern Med 2006, 166:955-964.

28. Chilsholm-Burns MA, Lee JK, Spivey CA, Slack M, Herrier RN, Hall-Lipsy E, Zivin JG, Abraham I, Palmer J, Martin JR, Kramer SS, Wunz T: US pharmacists' effect as team members on patient care: systematic review and meta-analyses. Med Care 2010, 48:923-933.

29. Altavela $J \mathrm{~L}$, Jones MK, Ritter M: A prospective trial of a clinical pharmacy intervention $\mathrm{n}$ a primary care practice in a capitated payment system. J Manag Care Pharm 2008, 14:831-843.

30. Carter BL, Rogers M, Daly J, Zheng S, James PA: The potency of team-based care interventions for hypertension: a meta-analysis. Arch Inter Med 2009, 21:1748-1755.
31. Carter BL, Ardery G, Dawson JD, James PA, Bergus GR, Doucette WR, Chrischilles EA, Franciscus $C L$, Xu Y: Physician and pharmacist collaboration to improve blood pressure control. Arch Intern Med 2009, 23:1996-2002.

32. Farris KB, Cote I, Feeny D, Johnson JA, Tsuyuki RJ, Brilliant S, Dieleman I: Enhancing primary care for complex patients: demonstration project using multidisciplinary team. Can Fam Physician 2004, 50:998-1003.

33. Bogden PE, Abbott D, Williamson P, Onopa JK, Koontz LM: Comparing standard care with a physician and pharmacist team approach for uncontrolled hypertension. J Gen Intern Med 1998, 13:740-745.

34. Ramalho de Oliveira D, Brummel AR, Miller DB: Medication therapy management: 10 years of experience in a large integrated health care system. J Manage Care Pharm 2010, 16:185-195.

35. Anderegg SV, DeMik DE, Carter BL, Dawson JE, Farris K, Shelsky C, Kaboli P: Acceptance of recommendations by inpatient pharmacy case manager: unintended consequences of hospitalist and specialist care. Pharmacother 2013, 33:11-21.

36. Israel EN, Farley TM, Farris KB, Carter BL: Under-utilization of cardiovascular medications: lack of effect of a continuity of care program. Am J Health-Sys Pharm 2013, 70:1592-1600.

37. Gillepsie U, Alassaad A, Henrohn D, Garmo H, Hammarlund-Udenaes M, Toss H, Kettis-Lindblad A, Melhus H, Morlin C: A comprehensive pharmacist intervention to reduce morbidity in patients 80 years or older: a randomized controlled trial. Arch Intern Med 2009, 169:894-900

38. Koechler BE, Richter KM, Youngblood L, Cohen BA, Prengler ID, Cheng D, Masica AL: Reduction in 30-day postdischarge hospital readmission or emergency department (ED) visit rates in high-risk elderly medical patients through delivery of a targeted care bundle. J Hosp Med 2009, $4: 211-218$.

doi:10.1186/1472-6963-14-406

Cite this article as: Farris et al:: Effect of a care transition intervention by pharmacists: an RCT. BMC Health Services Research 2014 14:406.

\section{Submit your next manuscript to BioMed Central and take full advantage of:}

- Convenient online submission

- Thorough peer review

- No space constraints or color figure charges

- Immediate publication on acceptance

- Inclusion in PubMed, CAS, Scopus and Google Scholar

- Research which is freely available for redistribution 